\title{
Effects of Preoperative Platelet Count on Blood Loss for Splenectomy with Esophagogastric Devascularization
}

\author{
Geng Bo, Piyush Kumar Mishra, Luo Chen, Yang Xian Mo, Ting Yan and Shiqiao Luo* \\ Department of Hepatobiliary Surgery, The First Affiliated Hospital, Chongqing Medical University, Yixueyuan Road, Yuzhong District, Chongqing, P. R. China
}

*Corresponding author: Shiqiao Luo, Department of Hepatobiliary Surgery, The First Affiliated Hospital, Chongqing Medical University, Yixueyuan Road, Yuzhong District, Chongqing, P. R. China, Tel: 86-23-68485041; E-mail: shiqiaoluo@qq.com

Received date: Apr 29, 2016, Accepted date: May 23, 2016, Publication date: May 26, 2016

Copyright: $\odot 2016$ Bo G, et al. This is an open-access article distributed under the terms of the Creative Commons Attribution License, which permits unrestricted use, distribution, and reproduction in any medium, provided the original author and source are credited.

\begin{abstract}
Objective: To investigate whether low preoperative platelet count increased blood loss in splenectomy and esophagogastric devascularization for hepatitis B cirrhosis patients, and to discuss the necessity of prophylactic platelet transfusion in patients with platelet count less than $50 \times 10^{9} / \mathrm{L}$.
\end{abstract}

Methods: 105 patients who received splenectomy from January 2008 to July 2014 were divided into three groups based on their preoperative platelet counts: <30 × 109/L (group 1), 30-50 × 109/L (group 2), >50 × 109/L (group 3). Their operation time, blood loss, postoperative platelet count of 1st and 3rd day, drainage volume, postoperative hospital stay and operation associated complications were compared between the 3 groups.

Results: Compared with patients in group 3, patients in group 1 and 2 experienced more blood loss, but the difference was not statistically significant $(P>0.05)$. There were no significant differences among 3 groups in terms of operative time, postoperative drainage, postoperative hospital stay and operation-associated complications $(\mathrm{P}>0.05)$. Compared with preoperative results, PLT count increased significantly after the operation between the 3 groups $(P<0.05)$.

Conclusion: It is safe to perform splenectomy and esophagogastric de-vascularization in hepatitis B cirrhosis patients with PLT count less than $50 \times 10^{9} / \mathrm{L}$, and also in patients with platelet count lower than $30 \times 10^{9} / \mathrm{L}$, it is not necessary to give prophylactic platelet transfusion until patient has any risk of bleeding.

Keywords: Liver cirrhosis; Platelet; Hypersplenism; Portal hypertension; Splenectomy

\section{Introduction}

Hepatitis B cirrhosis is defined as the histological development of regenerative nodules surrounded by fibrous bands due to hepatitis $B$ virus (HBV) [1,2]. It has been estimated 1 million deaths yearly worldwide from complications for liver cirrhosis [3,4]. Cirrhosis accounts for $90 \%$ of portal hypertension [5]. Hypersplenism and esophagogastric varices are most common clinical manifestations of liver cirrhosis and portal hypertension [6-8]. Hypersplenism leads to decrease in platelet counts, leukocyte counts and rapidly destruct the blood cells [9]. Severe thrombocytopenia due to hypersplenism significantly increases the risk of spontaneous bleeding and can postpone diagnostic or therapeutic procedures for cirrhosis patients, for instance, liver biopsy, interferon therapy and surgery [1].

Splenectomy and esophagogastric devascularization has been considered the effective therapy for liver cirrhosis $[6,10,11]$. It can not only cure hypersplenism and consequently abolish bleeding tendency due to thrombocytopenia, but also prevent bleeding from esophagogastric varices. Institute of German Medical Association and the American Association of blood banks recommend prophylactic platelet transfusion in liver cirrhosis patients with preoperative platelet counts less than $50 \times 10^{9} / \mathrm{L}[12,13]$. On the other side American Society of Clinical Oncology recommends the threshold value of prophylactic platelet transfusion with platelet counts $<10 \times 10^{9} / \mathrm{L}[14]$. But the recommendation remain controversial. We conducted this study to investigate the safety of splenectomy and esophagogastric devascularization for hepatitis B cirrhosis patients with platelet count less than $50 \times 10^{9} / \mathrm{L}$.

\section{Materials and Methods}

From January 2008 to July 2014 open splenectomy and esophagogastric devascularization were performed for hepatitis B cirrhosis on patients by matured and experienced surgeons at the department of Hepato-Bilio-Pancreatology, 1st Affiliated Hospital of Chongqing Medical University, Chongqing, China. We chose 105 patients, among them 63 were males and 42 were females. For investigation in those 105 patients Preoperative endoscopic ultrasound, CT scan and bone marrow smear test were performed, in which CT scan revealed significant splenomegaly and cirrhosis of the liver in all patients, endoscopic ultrasound showed small to large esophagogastric varices and bone marrow smear excluded hematopoietic disorders [15].

Demographic characteristics, laboratory data and histopathological data for all patients, with preoperative diagnosis of hepatitis B cirrhosis, who underwent splenectomy and devascularization between 2008 to 2014 were retrieved from the medical and histopathological records at the 1st Affiliated Hospital of Chongqing Medical University, Chongqing, China. We collected, Preoperative data including PLT 
Citation: Bo G, Mishra PK, Chen L, Mo YX, Yan T, et al. (2016) Effects of Preoperative Platelet Count on Blood Loss for Splenectomy with Esophagogastric Devascularization. J Blood Disord Transfus 7: 355. doi:10.4172/2155-9864.1000355

Page 2 of 6

counts, PT, albumin, spleen size, child-Pugh scores, portal vein diameter, total bilirubin/direct bilirubin. Existence of ascites or hepatic encephalopathy was also revealed preoperatively. Intraoperative data including blood loss, PLT transfusion rate and operation time. Postoperative data including drainage volume, PLT count on 1st and $3^{\text {rd }}$ day, postoperative complications and hospital stays (day). All patients were divided into 3 groups based on their preoperative platelet counts.

\section{Operation procedures}

Splenectomy and esophagogastric devascularization were performed by the surgical team of Hepato-Bilio-Pancreatology department. A modified Hassab's surgery was performed to treat esophageal varices in patients with portal hypertension as a result of cirrhosis of the liver [16,17]. Splenic artery was ligated, using traditional ligature and severed before splenectomy, vessels of upper half stomach and 6-10 cm distal esophagus were severed, no pyeloroplasty was carried out and a drainage tube was placed under the left diaphragm [17].

\section{Statistical analysis}

Numerical values were expressed as mean \pm standard deviation. Statistical analyses were performed by using SPSS20.0 for windows. Statistical comparisons between pre-operative and post-operative platelet count were made by using student's t-test and the chi-square test. Values of $\mathrm{p}$ less than 0.05 were considered statistically significant.

\section{Results}

Demographic characteristics on comparison of preoperative values among the three groups are shown in Table 1.

Group 1 and group 2 has shown noticeably lower platelet counts on comparison with group 3 (22.4 [range, 7-29] vs. 65.5 [range, 50-152], $\mathrm{p}<0.001)$, (41.3 [range, 31-49] vs. 65.5 [range, 50-152], $\mathrm{p}<0.001)$, the differences came out on comparison between the three groups in terms of age, HB, PT, Alb, BMI, spleen size, portal vein diameter (PVD) and Child-Pugh score.

\begin{tabular}{|c|c|c|c|c|c|}
\hline Variables & Group 1 & Group 2 & Group 3 & pa & $\mathrm{Pb}$ \\
\hline Cases & 26 & 43 & 36 & - & - \\
\hline $\operatorname{Sex}(F / M)$ & Jun-20 & $21 / 22$ & $16 / 20$ & NS & NS \\
\hline Age $(y)$ & $49.5(24-68)$ & $47.0(21-82)$ & $49.9(23-73)$ & NS & NS \\
\hline $\mathrm{Hb}(\mathrm{g} / \mathrm{L})$ & $96.0(77-124)$ & $101.4(70-145)$ & $95.4(57-128)$ & NS & NS \\
\hline PLT $\left(\times 10^{9} / \mathrm{L}\right)$ & $22.4(7-29)$ & $41.3(31-49)$ & $65.5(50-152)$ & 0.001 & 0.001 \\
\hline PT (s) & $16.2(12.1-19.6)$ & $15.6(12.4-21.3)$ & $15.5(12.0-18.0)$ & NS & NS \\
\hline Alb (g/L) & $34.4(27-45)$ & $35.8(21-44)$ & $35.6(21-51)$ & NS & NS \\
\hline BMI $\left(\mathrm{kg} / \mathrm{m}^{2}\right)$ & $22(18-29)$ & $23(19-27)$ & $22(17-28)$ & NS & NS \\
\hline \multicolumn{6}{|l|}{ Child-Pugh class } \\
\hline A & 15 & 35 & 27 & & \\
\hline B & 11 & 7 & 9 & & \\
\hline c & 0 & 1 & 0 & & \\
\hline Child-Pugh score & $6.3(5-9)$ & $5.8(5-11)$ & $5.9(5-8)$ & 0.085 & 0.749 \\
\hline Spleen size $(\mathrm{cm})$ & $20.1(10-35)$ & $19.0(12-25)$ & 18.1(11-27) & NS & NS \\
\hline Portal vein diameter $(\mathrm{mm})$ & $16.9(11-24)$ & $16.2(11-22)$ & $16.7(10-22)$ & NS & NS \\
\hline $\begin{array}{l}\text { Data are presented as med } \\
\text { Pa comparison between gr } \\
\text { Pub comparison between } 9 \\
\text { NS not significant }\end{array}$ & less otherwise indic & & & & \\
\hline
\end{tabular}

Table 1: Demographic characteristics.

A comparison of operative outcomes and postoperative details between three groups are shown in Table 2. Compared with patients in group 3, patients of group 1 had more blood loss (682.7 [range 100-2000] vs. $544.7 \mathrm{ml}$ [range 50-1800], $\mathrm{p}=0.334$ ), but the difference was not statistically significant. On comparison of group 1 with group 3 in terms of operation time (199.4 [range 95-460] vs. $197.5 \mathrm{~min}$ [range
60-360]], $\mathrm{p}=0.806)$, drainage volume of the 1st postoperative day (207.9 [range 5-480] vs. $176.6 \mathrm{ml}$ [range 2-970], $\mathrm{p}=0.477$ ), drainage volume of the $3^{\text {rd }}$ postoperative day (136.9 [range 0-750] vs. $137.1 \mathrm{ml}$ [range 0-610], $\mathrm{p}=0.996$ ), postoperative hospital stays of the two groups has shown no statistically significant (13.8 [range 8-28] vs. 13.6 day [range 8-32], $\mathrm{p}=0.888$ ). There were no significant differences on 
comparison of group 2 and group 3 in terms of blood loss (678.1 [range 50-3000] vs. $544.7 \mathrm{ml}$ [range 50-1800], $\mathrm{p}=0.295$ ) operation time (203.8 [range 75-400] vs. 197.5 min [range 60-360], p=0.644), 1st day postoperative drainage (189.4 [range 10-600] vs. $176.6 \mathrm{ml}$ [range 2-970], $\mathrm{p}=0.437)$ and hospital stays (14.6 days [range 6-30] vs. 13.6 days [range 8-32], $\mathrm{p}=0.721)$, 3rd day postoperative drainage $(181.9 \mathrm{ml}$ [range $0-1600$ ] vs. $137.1 \mathrm{ml}$ [range 0-610], $\mathrm{p}=0.437$ ) and hospital stays (14.1 [range 6-30] vs. 13.6 [range 8-32], $\mathrm{p}=0.742$ ). In group 1, 6 patients received intraoperative PLT transfusion, among them 3 patients experienced more than $1000 \mathrm{ml}$ blood loss, the other two suffered blood loss of $505 \mathrm{ml}, 220 \mathrm{ml}$. In group 2, 4 patients received intraoperative PLT transfusion, as 2 patients experienced blood loss of more than $800 \mathrm{ml}$ and the other two suffered blood loss of $600 \mathrm{ml}, 200$ $\mathrm{ml}$ respectively. In group 3, 2 patients received PLT transfusion, as their blood loss was $810 \mathrm{ml}, 220 \mathrm{ml}$ respectively.

\begin{tabular}{|c|c|c|c|c|c|}
\hline Variables & Group 1 & Group 2 & Group 3 & pa & $\mathrm{Pb}$ \\
\hline Operation (min) & $199.4(95-460)$ & $203.8(75-400)$ & $197.5(60-360)$ & NS & NS \\
\hline $\mathrm{EBL}(\mathrm{ml})$ & $682.7(100-2000)$ & $678.1(50-3000)$ & $544.7(50-1800)$ & NS & NS \\
\hline Platelet transfusion & May-26 & Apr-43 & Feb-36 & NS & NS \\
\hline POD 1 PLT & $72.2(20-222)$ & $94.6(33-240)$ & $100.9(31-198)$ & 0.009 & NS \\
\hline POD 3 PLT & $124.8(28-336)$ & $177.0(55-300)$ & $224.3(58-532)$ & 0.001 & NS \\
\hline POD 1 drain exudates (ml) & $207.9(28-336)$ & $189.4(10-600)$ & $176.6(2-970)$ & NS & NS \\
\hline POD 3 drain exudates (ml) & $136.9(0-750)$ & $181.9(0-1600)$ & $137.1(0-610)$ & NS & NS \\
\hline PHS (days) & $13.8(8-28)$ & $14.1(6-30)$ & $13.6(8-32)$ & NS & NS \\
\hline $\begin{array}{l}\text { Data are presented as medi } \\
\text { EBL estimated blood loss, } \mathrm{P} \\
\mathrm{Pa} \text { comparison between gro } \\
\mathrm{Pb} \text { comparison between gro } \\
\mathrm{NS} \text { not significant }\end{array}$ & ay, PHS postoperati & & & & \\
\hline
\end{tabular}

Table 2: Operative outcomes and postoperative details.

Postoperative complications of patients among three groups are shown in Table 3. In this study a total number of 31 patients experienced postoperative complications, 11 patients in group 1 $(42.3 \%), 12$ patients in group $2(28 \%), 8$ patients in group $3(22.2 \%)$. No any patient died of operation related complications in our study. One patient in group 1 suffered postoperative bleeding, peripheral vascular hemorrhage of pancreas was found on repeated surgery, bleeding stopped after suturing of vessels, and was discharged on the 10th postoperative day. 3 patients experienced splenic venous thrombus, 2 patients with pancreatic leakage, 2 patients developed pleural fluid postoperatively and were treated with conservative treatment and discharged. One 44 year old male patient in the group 1 with two complications, bacterial peritonitis and lung infection having preoperative PLT count of $24 \times 10^{9} / \mathrm{L}$, child-Pugh score 6 , operation time $170 \mathrm{~min}$, intraoperative bleeding $500 \mathrm{ml}$, has not received any blood transfusions during and after surgery. Anti-infection treatment were given to the patient after surgery and discharged from the hospital on $27^{\text {th }}$ day. In group 2, 6 patients were complicated with splenic vein thrombosis and 2 complicated with portal vein thrombosis, 2 patients experienced postoperative wound infection, 1 with pleural fluid, 1 with bacterial peritonitis, all the patients received conservative treatment and discharged from hospital. A prolonged stay in hospital after surgery, a 36 years old male patient with preoperative PLT $45 \times 10^{9} / \mathrm{L}$, child-Pugh score 5 , operation time $90 \mathrm{~min}$, intraoperative bleeding $100 \mathrm{ml}$, postoperative wound infection, was given conservative treatment and discharged on the $30^{\text {th }}$ day. In group 3,2 patients with pleural effusion, 2 cases with pulmonary infection, 2 cases of postoperative wound infection, 1 case of urinary tract infections and 1 case of splenic vein thrombosis, were treated by conservative treatment and discharged from hospital. Overall, among all the patients in three groups, patients of group 1 had much higher operation associated complications than other two groups, but the differences were not statistically significant.

\begin{tabular}{|c|c|c|c|c|c|}
\hline Complications & Group 1 & Group 2 & Group 3 & pa & $\mathrm{Pb}$ \\
\hline Postoperative bleeding & 1 & 0 & 0 & & \\
\hline Splenic vein thrombus & 3 & 6 & 1 & & \\
\hline Pancreatic leakage & 2 & 0 & 0 & & \\
\hline Pleural effusion & 2 & 1 & 2 & & \\
\hline
\end{tabular}


Citation: Bo G, Mishra PK, Chen L, Mo YX, Yan T, et al. (2016) Effects of Preoperative Platelet Count on Blood Loss for Splenectomy with Esophagogastric Devascularization. J Blood Disord Transfus 7: 355. doi:10.4172/2155-9864.1000355

Page 4 of 6

\begin{tabular}{|c|c|c|c|c|c|}
\hline Peritonitis & 1 & 1 & 0 & & \\
\hline Pulmonary infection & 1 & 0 & 2 & & \\
\hline Incision infection & 1 & 2 & 2 & & \\
\hline Portal venous thrombosis & 0 & 2 & 0 & & \\
\hline Ureter infection & 0 & 0 & 1 & & \\
\hline Total & $11(42.3 \%)$ & $12(28.0 \%)$ & $8(22.2 \%)$ & NS & NS \\
\hline \multicolumn{6}{|l|}{ Data are presented as $\mathrm{n}(\%)$} \\
\hline \multicolumn{6}{|c|}{ Pa comparison between group 1 and group 3} \\
\hline \multicolumn{6}{|c|}{$\mathrm{Pb}$ comparison between group 2 and group 3} \\
\hline
\end{tabular}

Table 3: Complications.

Patients of the three groups with postoperative changes in platelets are shown in Table 4. We found significant difference on comparison of preoperative platelet counts with postoperative platelet counts, as platelet counts improved significantly in patients of all the three groups post-operatively. Pre and postoperative platelet counts changes in group 1 to (22.4 [range 7-29] vs. 124.8 [range 28-336], $\mathrm{p}<0.001)$, group
2 to (41.3 [range 31-49] vs. 177.0 [range 55-300], $\mathrm{p}<0.001)$, group 3 to (65.5 [range 50-152] Vs. 224.3 [range 58-532], $\mathrm{p}<0.001)$.

There was significant improvement in platelet count after $72 \mathrm{~h}$ of splenectomy $(<0.05)$.

\begin{tabular}{|l|l|l|l|}
\hline & $\mathbf{1}$ day pre-operation & $\mathbf{3}$ days post operation & $\mathbf{P}$ \\
\hline Group 1 & $22.4(7-29)$ & $124.8(28-336)$ & 0.001 \\
\hline Group 2 & $41.3(31-49)$ & $177.0(55-300)$ & 0.001 \\
\hline Group 3 & $65.5(50-152)$ & $224.3(58-532)$ & 0.001 \\
\hline $\begin{array}{l}\text { Data are presented as median (range) } \\
\text { P shows comparison between preoperative and postoperative values } \\
\text { NS not significant }\end{array}$ & & \\
\hline
\end{tabular}

Table 4: Changes in platelet counts after the operation.

\section{Discussion}

Chronic hepatitis B virus (HBV) infection is a major global public health problem with an estimated 1 million deaths yearly worldwide from complications of liver cirrhosis. The prognosis for patients with decompensated HBV cirrhosis is poor, with a 5-year survival of only $14 \%$ compared with $84 \%$ in patients with compensated HBV cirrhosis [3]. Hypersplenism, splenomegaly and portal hypertension are common complications of liver cirrhosis associated with HBV. Hypersplenism often led to thrombocytopenia, leukopenia and anemia. Treatment includes drug therapy, liver transplantation, splenic artery embolization and resection of spleen for hypersplenism [18]. However Djordjević et al. [19] reported in his studies that there is no any correlation between spleen size and platelet counts [19]. Splenectomy is indicated when the platelet count goes below $30 \times$ $10^{9} / \mathrm{L}$ [20]. In 1950 for the first time open splenectomy was performed and was considered feasible and safe for liver cirrhosis after development of more than 60 years [21-23]. The main purpose of open splenectomy for portal hypertension is: (1) to reduce portal vein blood flow, relieve portal hypertension, to improve esophagogastric varices bleeding [24]. (2) To improve hypersplenism induced thrombocytopenia [10]. (3) To improve the treatment of hepatocellular carcinoma [25]. (4) Splenectomy is favorable for overcoming small-forsize (SFS) graft syndrome in living donor liver transplantation [26,27]. Multiple studies indicate that splenectomy for liver cirrhosis has many benefits. Murata et al. [28] reported albumin, cholinesterase, total cholesterol and liver volume raised 6 months after splenectomy in 12 patients with liver cirrhosis, author considered that splenectomy may be helpful to improve liver function in patients with liver cirrhosis and could be a transitional treatment for patients waiting for liver transplantation [28]. Kawanaka et al. [29] believes that in patients with liver cirrhosis and portal hypertension, splenectomy reduced portal venous pressure. A decrease in splanchnic blood flow, by eliminating splenic blood flow and reduction in intrahepatic vascular resistance, by normalizing hepatic concentrations of ET-1 and NOx, may both have contributed. Anegawa et al. [29] reported that splenectomy significantly decreased portal venous pressure and improves childPugh score [29].

Thrombocytopenia induced by hypersplenism increases the risk of spontaneous bleeding caused by rupture of esophagogastric varices, which is the most life-threatening complication of liver cirrhosis and is responsible for approximately $1 / 3$ percent of total number of deaths in cirrhosis after hepatitis B. Acute esophageogastric varices bleeding is 
associated with a mortality rate of approximately 25-30\% [1]. Although clinical significant spontaneous bleeding does not occur until the platelet count is less than $10 \times 10^{9} / \mathrm{L}$ [21]. In order to prevent esophagogastric bleeding for liver cirrhosis patients, splenectomy and esophagogastric devascularization is performed for them. Institute of German Medical Association and the American Association of blood banks recommends prophylactic platelet transfusion in liver cirrhosis patients with preoperative platelet counts less than $50 \times 10^{9} / \mathrm{L}[11,12]$. However the prophylactic platelet transfusion in patients with preoperative platelet count below $50 \times 10^{9} / \mathrm{L}$ remains controversial, some scholars believe, it is difficult to assess the role of platelet transfusion in clinical practice, because other potential factors can also cause bleeding during the operation (such as drugs, renal insufficiency, vWF) $[30,31]$. At present, the platelets are extremely rare blood products and at the same time many adverse effects are associated with platelet transfusion, such as fever, allergies, kidney failure, thrombosis and embolism [32]. In addition, recent studies have shown that, platelet transfusion may cause inflammatory and immune responses and may have negative effects on prognosis of malignant diseases [12].

To investigate the effects of preoperative platelet counts on blood loss for splenectomy and esophagogastric devascularization in hepatitis B associated cirrhosis patients with preoperative platelet counts less than $50 \times 10^{9} / \mathrm{L}, 105$ patients were retrospectively divided into 3 groups based on their preoperative platelet counts: $<30 \times 10^{9} / \mathrm{L}$ (group 1), $30-50 \times 10^{9} / \mathrm{L}($ group 2$),>50 \times 10^{9} / \mathrm{L}$ (group 3). Liver cirrhosis is often associated with thrombocytopenia, hypersplenism associated with splenomegaly, coagulation disorder and high risk of intraoperative bleeding. As per to reduce the intraoperative bleeding, treatment were given to patients with poor liver function in manner to improve the child-pugh score [33]. In the separation of perisplenic ligaments and blood vessels, careful action were taken for hemostasis to ensure clear vision. We compared three groups to find whether there were differences in operation time, intra-operative bleeding volume, postoperative platelet counts and postoperative hospital stays. Among three groups, group 1 suffered more blood loss than other two groups but the differences were not statistically significant. There were no statistically significant differences between three groups in terms of operation time, drainage volumes, operation associated complications and hospital stays. But, PLT counts increased significantly post splenectomy in all the three groups on comparison with preoperative PLT counts and came to its normal level on $3^{\text {rd }}$ day. Follow-up data requires further investigation whether the platelet counts can be maintained at a normal level for a long time.

In summary, the retrospective study we performed has some limitations. Data are not complete and this limits the power of statistical calculations. Not all the patients characteristics initially planned at the beginning of the study could be addressed in the statistical analysis due to a lack of data. Lack of some evidence like portal venous pressure and number of collateral vessels may affect our study. However, despite these limitations we think that the results of this study can be useful.

The strong relationship between portal venous pressure and number of collateral vessels should be investigated further to explore the role of prophylactic platelet transfusion during intraoperative blood loss. But, we suggest that with sufficient preoperative preparation and careful operation, splenectomy and esophagogastric devascularization can be performed in hepatitis B associated cirrhosis in patients with PLT counts less than $50 \times 10^{9} / \mathrm{L}$. Hence, it is not necessary to give prophylactic platelet transfusion until patient has any risk of bleeding, as it does not bleed until the platelet count is less than $10 \times 10^{9} / \mathrm{L}$ or 20 $\times 10^{9} / \mathrm{L}$. But the safe level of platelet count remain uncertain in cirrhosis patients for platelet transfusion pre splenectomy.

\section{Conclusion}

According to our study we suggest that performing splenectomy and esophagogastric devascularization in hepatitis B cirrhosis patients with PLT count less than $50 \times 10^{9} / \mathrm{L}$ and $30 \times 10^{9} / \mathrm{L}$, may improve the platelet counts postoperatively and it is not necessary to give prophylactic platelet transfusion until patient has any incidence of bleeding.

\section{References}

1. Cai YQ, Zhou J, Chen XD, Wang YC, Wu Z, et al. (2011) Laparoscopic splenectomy is an effective and safe intervention for hypersplenism secondary to liver cirrhosis. Surg Endosc 25: 3791-3797.

2. Malhotra R, Soin D, Grover P, Galhotra S, Khutan H, et al. (2016) Hepatitis B virus and hepatitis C virus co-infection in hemodialysis patients: A retrospective study from a tertiary care hospital of North India. J Nat Sci Biol Med 7: 72-74.

3. Guan R, Lui HF (2011) Treatment of hepatitis B in decompensated liver cirrhosis. Int J Hepatol 2011: 918017.

4. Datta S (2008) An overview of molecular epidemiology of hepatitis B virus (HBV) in India. Virol J 5: 156.

5. Bosch J, Abraldes JG, Berzigotti A, Garcia-Pagan JC (2008) Portal hypertension and gastrointestinal bleeding. Semin Liver Dis 28: 3-25.

6. Zheng X, Dou C, Yao Y, Liu Q (2015) A meta-analysis study of laparoscopic versus open splenectomy with or without esophagogastric devascularization in the management of liver cirrhosis and portal hypertension. J Laparoendosc Adv Surg Tech A 25: 103-111.

7. Sarin SK, Lahoti D, Saxena SP, Murthy NS, Makwana UK (1992) Prevalence, classification and natural history of gastric varices: A longterm follow-up study in 568 portal hypertension patients. Hepatology 16: 1343-1349.

8. Armonis A, Patch D, Burroughs AK (1997) Hepatic venous pressure measurement: An old test as new prognostic marker in cirrhosis? Hepatology 2: 245-248.

9. Elmakki E (2012) Hypersplenism: Review article. Journal of Biology, Agriculture and Healthcare 2: 10.

10. Yaccobe LM, Jaqua NT, Kenny P (2013) Successful treatment of bleeding gastric varices with splenectomy in a patient with splenic, portal, and mesenteric thromboses. Case Rep Surg 3: 273531.

11. Kedia S, Goyal R, Mangla V, Kumar A, Das P, et al. (2012) Splenectomy in cirrhosis with hypersplenism: improvement in cytopenias, child's status and institution of specific treatment for Hepatitis C with success. Ann Hepatol 11: 921-929.

12. Wandt H, Schäfer-Eckart K, Greinacher A (2014) Platelet transfusion in hematology, oncology and surgery. Dtsch Arztebl Int 111: 809-815.

13. Kaufman RM, Djulbegovic B, Gernsheimer T, Kleinman S, Tinmouth AT, et al. (2015) Platelet transfusion: a clinical practice guideline from the AABB. Ann Intern Med 162: 205-213.

14. Schiffer CA, Anderson KC, Bennett CL, Bernstein S, Elting LS, et al. (2001) Platelet transfusion for patients with cancer: clinical practice guidelines of the american society of clinical oncology. J Clin Oncol 19: 1519-1538.

15. Spiegel BM, Esrailian E, Eisen G (2007) The budget impact of endoscopic screening for esophageal varices in cirrhosis. Gastrointest Endosc 66: 679-692.

16. Liu Y, Li Y, Ma J, Lu L, Zhang L (2013) A modified Hassab's operation for portal hypertension: experience with 562 cases. J Surg Res 18: 463-468. 
Citation: Bo G, Mishra PK, Chen L, Mo YX, Yan T, et al. (2016) Effects of Preoperative Platelet Count on Blood Loss for Splenectomy with Esophagogastric Devascularization. J Blood Disord Transfus 7: 355. doi:10.4172/2155-9864.1000355

Page 6 of 6

17. Hassab MA (1967) Gastro-esophageal decongestion and splenectomy in the treatment of esophageal varices in bilharzial cirrhosis: further studies with a report on 355 operations. Surgery 61: 170.

18. Jin S, Dai CL (2010) Splenectomy in patients with liver cirrhosis and portal hypertension. World Chinese Journal of Digestology 18: 3533-3538.

19. Djordjevic J, Svorcan P, Vrinic D, Dapcevic B (2010) Splenomegaly and thrombocytopenia in patients with liver cirrhosis. Vojnosanit Pregl 67: 166-169.

20. Watanabe Y, Horiuchi A, Yoshida M, Yamamoto Y, Sugishita H, et al. (2007) Significance of laparoscopic splenectomy in patients with hypersplenism. World J Surg 31: 549-555.

21. Hayashi H, Beppu T, Shirabe K, Maehara Y, Baba H (2014) Management of thrombocytopenia due to liver cirrhosis: a review. World J Gastroenterol 20: 2595-2605.

22. Lord JW Jr (1951) The surgical management of secondary hypersplenism. Surgery 29: 407-418.

23. Linton RR, Ellis DS, Geary JE (1961) Critical comparative analysis of early and late results of splenorenal and direct portacaval shunts performed in 169 patients with portal cirrhosis. Ann Surg 154: 446-459.

24. Hashizume M, Tomikawa M, Akahoshi T, Tanoue K, Gotoh N, et al. (2002) Laparoscopic splenectomy for portal hypertension. Hepatogastroenterology 49: 847-852.

25. Sugawara Y, Yamamoto J, Shimada K, Yamasaki S, Kosuge T, et al. (2000) Splenectomy in patients with hepatocellular carcinoma and hypersplenism. J Am Coll Surg 190: 446-450.

26. Yoshizumi T, Taketomi A, Soejima Y, Ikegami T, Uchiyama H, et al. (2008) The beneficial role of simultaneous splenectomy in living donor liver transplantation in patients with small-for-size graft. Transpl Int 21: 833-842.

27. Sibulesky L, Nguyen JH, Paz-Fumagalli R, Taner CB, Dickson RC (2009) Treatment modalities for hypersplenism in liver transplant recipients with recurrent hepatitis C. World J Gastroenterol 15: 5010-5013.

28. Murata K, Ito K, Yoneda K, Shiraki K, Sakurai H, et al. (2008) Splenectomy improves liver function in patients with liver cirrhosis. Hepatogastroenterology 55: 1407-1411.

29. Anegawa G, Kawanaka H, Uehara H, Akahoshi T, Konishi K, et al. (2009) Effect of laparoscopic splenectomy on portal hypertensive gastropathy in cirrhotic patients with portal hypertension. J Gastroenterol Hepatol 24: 1554-1558.

30. Kumar A, Mhaskar R, Grossman BJ, Kaufman RM, Tobian AA, et al. (2015) Platelet transfusion: a systematic review of the clinical evidence. Transfusion 55: 1116-1127.

31. Ghweil AA, Arafa UA, Khodeary A, Salem AN (2014) Predictors of bleeding from esophageal varices: the role of factor VII and Von Willebrand Factor (vWF). Open Journal of Gastroenterology 4: 152-158.

32. Cai Y, Liu X, Peng B (2014) Should we routinely transfuse platelet for immune thrombocytopenia patients with platelet count less than $10 \mathrm{x}$ 10(9)/L who underwent laparoscopic splenectomy. World J Surg 38: 2267-2272.

33. Pugh RN, Murray-Lyon IM, Dawson JL, Pietroni MC, Williams R (1973) Transection of the oesophagus for bleeding oesophageal varices. Br J Surg 60: 646-649. 